\title{
Instabilidade financeira em países em desenvolvimento: uma análise intersetorial *
}

\author{
Adriana Moreira Amado ** \\ Jean Toledo de Freitas ${ }^{* * *}$
}

\section{Resumo}

Este trabalho discute elementos conformadores de instabilidade financeira em países em desenvolvimento, buscando evidenciar mecanismos de incentivo que condicionam o comportamento dos diferentes setores presentes nas economias ao longo dos ciclos. É utilizada como referência a hipótese de fragilidade financeira de Minsky (1986), e avaliados aspectos estruturais que acentuam a fragilidade deste grupo de países, relacionados à sua forma de inserção comercial e financeira, num contexto de elevada liberdade de fluxos de capitais. Partindo do balanço estilizado e das principais relações financeiras intersetoriais em uma economia aberta, notam-se elementos que conduzem a uma postura procíclica por parte dos diferentes setores, elevando sua vulnerabilidade nos períodos de crescimento, a despeito dos diferentes objetivos de atuação dos setores público e privado. É ressaltada a relevância de instrumentos que contribuam para que o Estado constitua margens de manobra para atuar de modo anticíclico e reduzam sua exposição à oscilação dos fluxos internacionais de capitais.

Palavras-chave: Crises financeiras; Capital Fluxos de capitais; Economia pós-keynesiana; América Latina.

\begin{abstract}
Financial instabilty in developing countries: an intersectoral analysis

This paper discusses elements that contribute to financial instability in developing countries, evaluating incentive mechanisms that condition the behavior of different economic sectors over the cycles. Minsky's financial fragility hypothesis is used as a theoretical reference, in addition to an analysis of structural constraints that accentuate the fragility of this group of countries, related to their position in global commercial and financial systems, in an environment marked by freedom of capital movements. From the stylized balance and main financial intersectoral relations in an open economy, it is observed that different domestic sectors tend to present procyclical behavior, increasing their vulnerability in periods of growth, despite the different objectives of the public and private sectors. We highlight the relevance of instruments that provide the State with margins of maneuver for countercyclical policy actions, in order to reduce collateral effects from fluctuations in international capital flows.
\end{abstract}

Keywords: Financial crises; Capital flows; Post-Keynesian economics; Latin America.

JEL E12, E44, G01, O54.

\section{Introdução}

Os episódios de instabilidade financeira são recorrentes ao longo da história da economia capitalista, em diferentes locais e realidades institucionais (Kindleberger, 2000). De modo paradoxal, este é um assunto geralmente relegado a um segundo plano pela teoria econômica tradicional, que assume como pressuposto uma tendência natural ao equilíbrio,

\footnotetext{
* Artigo recebido em 9 de novembro de 2017 e aprovado em 19 de fevereiro de 2019. As opiniões expressas neste trabalho são exclusivamente do(s) autor(es) e não refletem, necessariamente, a visão do Banco Central do Brasil.

${ }^{* *}$ Professora titular do Departamento de Economia da Universidade de Brasília (UnB), Brasília, DF, Brasil. E-mail: uctpama@unb.br.

*** Servidor do Banco Central do Brasil, Brasília, DF, Brasil. E-mail: jeantfreitas@ yahoo.com.br.
} 
no nível de pleno emprego. O desvio dessa trajetória de tempos em tempos é normalmente atribuído a fatores exógenos, que podem ser corrigidos pelas próprias forças dos mercados (Minsky, 1986).

Diferentemente, numa perspectiva pós-keynesiana, o fenômeno da instabilidade financeira é visto como elemento central, inerente ao modo como se procedem as relações econômicas. De acordo com Minsky (1986), estes eventos decorrem do próprio modo como a estrutura financeira das unidades presentes na economia evolui ao longo dos períodos de crescimento, num contexto predominantemente incerto, no sentido empregado por Keynes (1936).

A transposição da análise para os países em desenvolvimento (PEDs) ${ }^{1}$ envolve elementos adicionais, que amplificam sua vulnerabilidade. Podem ser assinaladas assimetrias estruturais em relação aos países avançados, relacionadas ao modo que se inserem no contexto econômico global.

Do ponto de vista das relações de comércio, este ponto tem sido amplamente discutido pela escola estruturalista latino-americana (Prebisch, 1949; Furtado, 1961; entre outros). A especialização produtiva e comercial em produtos primários e de baixo teor tecnológico expõe os PEDs à conformação de desequilíbrios externos, em decorrência de sua menor capacidade geração e retenção de progresso técnico.

Do ponto de vista das relações de financiamento externo, pode ser ressaltada uma característica hierárquica e concentrada do sistema monetário internacional, e diferenças de complexidade e de dimensão das praças financeiras dos países avançados e em desenvolvimento (Prates, 2004; Akyüs, 2008; entre outros). Estes fatores contribuem para acentuar a dinâmica volátil e procíclica dos fluxos de capitais. Neste cenário, as economias periféricas tornam-se dependentes de elementos além da esfera de controle local, como é o caso de mudanças de políticas econômicas nos países avançados (Amado; Resende, 2007).

A análise das relações interfinanceiras entre os setores contribui para a compreensão da evolução da fragilidade em economias abertas, em especial nos PEDs. A despeito de objetivos de atuação diferenciados sobre os setores privado e público, mecanismos de incentivo procíclicos operam sobre ambos, de modo amplificado ao cenário exposto por Minsky (1986). Neste aspecto, há perda de margens de ação anticíclica por parte do Estado, especialmente em economias com elevado grau de abertura financeira.

(1) Os termos "países em desenvolvimento" ou "periféricos", e "países centrais", ou "avançados" são utilizados de forma indistintas neste artigo, sem, contudo, ignorar que existem divergências entre as classificações e que os termos não são neutros. A distinção entre países centrais e periféricos, usualmente adotada em textos da tradição estruturalista cepalina, envolve uma discussão sobre o grau de complexidade de estruturas produtivas e da capacidade de geração e de retenção do progresso técnico, como discutido por Prebisch (1949). Os grupos de países possuem uma relação que embora seja complementar, é assimétrica, gerando um componente de reforço de suas características. A nomenclatura que divide os países entre "avançados" e "em desenvolvimento", geralmente adotada por organismos multilaterais, toma como ponto de partida variáveis associadas a indicadores como nível e concentração de renda per capita e qualidade de vida, como discutido por Nielsen (2011). Outra definição correntemente utilizada é a de "países emergentes", que de modo geral pode ser associada aos países periféricos que aumentaram seu grau de integração financeira internacional, como discutido por Prates (2004). Os termos "em desenvolvimento", "emergentes", e "avançados" trazem em sua própria composição uma percepção que pode induzir a uma interpretação do desenvolvimento como uma etapa, uma transição em direção ao grau de desenvolvimento pleno, diferenciando-se da visão estruturalista. Sua manutenção no texto decorre do reconhecimento de seu uso generalizado. 
Este trabalho tem por objetivo uma discussão sobre como as relações financeiras em uma economia aberta em desenvolvimento influenciam suas condições de estabilidade financeira. Como elemento de análise é utilizado um desenho esquemático simplificado sobre os principais saldos de balanço e transações financeiras intersetoriais numa economia aberta. $\mathrm{O}$ artigo está organizado da seguinte forma, além desta introdução. A primeira seção faz uma breve discussão teórica sobre os condicionantes para a emergência de instabilidade financeira, partindo sobretudo na hipótese de fragilidade financeira de Minsky (1986). A segunda seção aborda aspectos ligados à inserção no sistema econômico global dos PEDs, partindo de um referencial estruturalista. A terceira seção discorre sobre as relações assimétricas nas relações globais de financiamento externo, associadas à organização dos sistemas monetário e financeiro globais. A quarta seção busca retratar principais relações financeiras intersetoriais numa economia aberta e em desenvolvimento, por meio de um enfoque contábil estilizado, com vistas a avaliar como estímulos procíclicos operam sobre os setores domésticos. A última parte tece considerações finais a respeito de possíveis ações e desafios por parte do Estado.

\section{Crises financeiras numa perspectiva pós-keynesiana}

A publicação da Teoria Geral do Emprego, dos Juros e da Moeda, por Keynes em 1936 (Keynes, 1936) representou uma ruptura no estudo da macroeconomia em relação à teoria convencional então vigente (Blaug, 1997; Snowdown; Vane, 2005). A crítica aos "clássicos" e a introdução dos conceitos de demanda efetiva e de preferência pela liquidez representaram um ataque frontal à lei de Say e à visão de tendência natural da economia ao equilíbrio com pleno emprego (Davidson, 2005). A economia capitalista é caracterizada como inerentemente instável, em um contexto marcado pela presença da incerteza e no qual a moeda não é neutra e exerce papel relevante (Carvalho, 1988; Minsky, 1986).

No tocante à avaliação dos fatores que conduzem à conformação de períodos de crise, a obra de Minsky $(1975 ; 1986)$ é relevante. O autor integra aspectos centrais do corpo teórico de Keynes em relação ao processo de determinação dos investimentos, com elementos relativos ao comportamento dinâmico das relações financeiras entre as unidades econômicas, num contexto marcado pela incerteza e pela não neutralidade da moeda, criando uma "teoria financeira dos investimentos" (Papadimitrou; Wray, 2008). A economia capitalista é compreendida como inerentemente instável. A emergência de episódios de crise depende de fatores endógenos à própria dinâmica econômica ao longo dos períodos de crescimento. Dois pontos são fundamentais, a influência das expectativas na formação dos preços dos ativos de capital; e a evolução da estrutura financeira das diversas unidades econômicas presentes na economia.

Para Minsky (1986), as variações dos investimentos são parte essencial para a determinação dos níveis de renda e de emprego. Os elementos determinantes para a avaliação de sua viabilidade, à diferença da visão neoclássica, não derivam de circunstâncias objetivas. Como enfatizado por Mollo (1988), num contexto marcado pela presença da incerteza, a variação dos investimentos se associa ao caráter subjetivo das decisões capitalistas, cujas bases oscilam de acordo com o estado de expectativas vigentes. A decisão de investimentos é uma decisão especulativa, que envolve a abdicação de 
posições líquidas, mirando um montante de dinheiro superior ao original no futuro (money today, money later; Minsky, 1986, p. 251). Partindo de um cenário de expectativas convencionais, há a compreensão de que a exposição a risco das unidades evolui ao longo dos ciclos. Minsky (1986) descreve um processo de realimentação entre expectativas, decisões de investimentos e lucros. Períodos em que os lucros excedem as projeções pretéritas contribuem para um processo de ajuste de decisões correntes de investimentos e para a redução das margens de segurança. Assim, as expectativas futuras são a base para as decisões de investimentos e os resultados auferidos são elemento que validam ex post as decisões tomadas no passado e projetam as decisões futuras.

A estrutura de capitais ${ }^{2}$ considerada adequada se altera com o desenvolvimento das convenções prevalecentes. Um período inicial de expansão pode evoluir em direção a um boom especulativo, reforçado pela alavancagem crescente das unidades econômicas e pela alimentação das expectativas. De outra forma, uma situação em que predominam unidades hedge, expostas à variação dos fluxos de receitas, pode gradativamente ceder espaço a um contexto com unidades especulativas, suscetíveis também a variações das condições financeiras. A conformação de situações Ponzi pode ocorrer em virtude da frustração das expectativas otimistas pretéritas, ou da mudança das condições financeiras em relação ao período anterior, num contexto de compromissos financeiros crescentes.

Conforme unidades econômicas tipicamente especulativas migrem para uma condição Ponzi, novas posições de investimentos são desestimuladas, diante da reversão de expectativas quanto a sua rentabilidade futura ou da falta de capacidade de financiamento. A necessidade de rolagem em condições adversas de compromissos anteriormente assumidos pode gerar pressão de venda sobre os ativos não líquidos, acentuando a tendência contrativa. A percepção de piora das condições de pagamento faz com que os credores adotem posições mais cautelosas, com o aumento de suas margens de segurança, aumentando os custos de financiamento e reduzindo sua oferta de crédito. A combinação de redução dos investimentos, queda do valor dos ativos e dificuldades de refinanciamento acelera o processo de retração, podendo acarretar credit crunchs e redução da liquidez dos mercados.

Os bancos são parte importante nesta dinâmica. Facilitam o processo expansivo, e acentuam a vulnerabilidade. Imersos no mesmo ambiente de expectativas que os demais setores, competem de modo intenso entre si e com outras instituições financeiras, o que favorece a adoção de posições arriscadas e a criação de mecanismos de escape regulatórios

(2) Minsky (1986) descreve a evolução das estruturas financeiras predominantes numa economia em três estágios: Numa condição hedge, as receitas previstas são mais que suficientes para honrar os compromissos financeiros assumidos e financiar novas posições de investimentos. Numa condição especulativa, as receitas são superiores aos serviços de juros, porém inferiores ao total de saídas fluxos de caixa. O que torna uma posição especulativa sustentável são expectativas de que o fluxo total de receitas deduzidas dos compromissos financeiros seja positivo. Enquanto a viabilidade de uma estrutura hedge depende fundamentalmente da aderência das expectativas ao fluxo de receitas esperadas, uma unidade especulativa é contingente à não deterioração das condições financeiras sobre os passivos. Por fim, em estruturas Ponzi, as receitas esperadas são insuficientes inclusive para suportar o pagamento de juros, o que gera a necessidade de aumento da carga de dívidas e a alienação de ativos. O surgimento de unidades econômicas em situação Ponzi aumenta a vulnerabilidade de uma economia a processos de instabilidade, decorrentes, da incapacidade de honrar compromissos assumidos, com reflexos sobre a capacidade ou disposição dos bancos em conceder novas operações de crédito e sobre o funcionamento das cadeias de pagamento intersetoriais. 
(Freitas, 1997; Minsky, 1986). Conferem endogeneidade aos meios de pagamento ao expandirem suas operações de crédito, com a criação de moeda. De forma oposta, há destruição de moeda quando contraem suas atividades, dificultando o acesso a recursos por parte das unidades endividadas (Minsky, 1986).

A combinação de um cenário de elevado endividamento e de queda dos preços dos ativos nas fases de descenso dificulta o processo de ajuste dos agentes endividados, à medida que a tendência deflacionária dos preços eleva o valor real das dívidas. Pode ocorrer um processo típico de debt deflation, nos moldes colocados por Fisher (1933), com a divergência de o valor entre ativos e passivos, repúdio das dívidas e falências, podendo acarretar situações de pânico bancário e de depressão econômica.

Estes elementos fornecem justificativas para um papel ativo por parte do Estado, como elemento estabilizador. Nos períodos de tranquilidade, sua ação regulatória contribui para atenuar a tendência de tomada de posições excessivamente arriscadas por parte dos agentes privados, buscando que quebras individuais não resultem em efeitos sistêmicos (Freitas, 1997; Aglietta, 1998). Este ponto é válido em especial para o sistema bancário, dado o papel ao mesmo tempo virtuoso e desestabilizador que exerce (Freitas, 1997; Minsky, 1986).

Adicionalmente, Minsky (1986) ressalta que o governo pode ter um papel fundamental nos períodos de contração cíclica. Sua atuação como fonte de gasto autônomo (big government) contribui para a manutenção de um nível mínimo de demanda efetiva e de ancoragem das expectativas do setor privado. As autoridades monetárias (big bank) são fundamentais na condução das taxas de juros e como emprestadores de última instância, com o intuito de evitar colapsos dos sistemas de pagamento e dos mercados financeiros.

O reconhecimento de que a gestação de períodos de instabilidade é inerente às relações econômicas, a partir dos próprios períodos de crescimento, evidencia a dificuldade de construção de estruturas econômicas à prova de falhas. A subjetividade do processo decisório pelos setores privados cria elementos que atuam de modo procíclico sobre a formação das expectativas e que contribuem para que o auge cíclico seja geralmente acompanhado de aumento da sensação de segurança dos setores alavancados e para um comportamento mais frouxo em relação ao risco. Neste sentido, torna-se evidente a necessidade de mecanismos que atuem em sentido contrário à tendência, como forma de atenuar a alternância entre períodos de euforia e pânico nas economias.

\section{Estruturalismo e vulnerabilidade externa}

A avaliação dos problemas econômicos dos PEDs envolve diferenciações em relação à realidade típica de economias avançadas. A observação a partir de um modelo geral dificulta a avaliação sobre os problemas econômicos destes países, que vão além da taxa de acumulação de capital. O histórico ao longo do último século, de maior volatilidade de taxas de crescimento e recorrentes episódios de vulnerabilidade externa, evidencia, como comentado por Ocampo (2011), uma dominância dos balanços de pagamentos como elemento conformador de instabilidades. O debate sobre a inserção dos PEDs na economia internacional é relevante na literatura heterodoxa. 
A visão estruturalista ressalta aspectos ligados à inserção dos PEDs no sistema econômico internacional como fonte de explicação do caráter subdesenvolvido destas economias e a vulnerabilidade externa decorrente, em especial na América Latina (Prebisch, 1949; Furtado, 1961; entre outros). A economia mundial é visualizada como um sistema amplo em que atuam países centrais, produtores de produtos manufaturados, e periféricos, produtores de produtos primários e de baixo teor tecnológico.

Prebisch (1949) nota que, embora os frutos do progresso técnico se distribuam de forma razoavelmente homogênea nos países industrializados, o mesmo não pode ser dito sobre os países produtores de matérias-primas. A intensificação do modelo de desenvolvimento para fora (hacia fuera), por parte dos países produtores de matériasprimas potencializa e consolida a divergência entre os grupos de países (Rodriguez, 1980). $\mathrm{O}$ atraso econômico não é fruto do isolamento econômico, mas da forma como os países estão inseridos na economia global.

Como discutido por Rodriguez (2009), diferentemente dos países avançados, cuja estrutura produtiva é relativamente homogênea e diversificada, os países periféricos são heterogêneos e especializados. Há um reduzido nível de vinculação entre a renda gerada pelos setores dinâmicos, ligados ao comércio externo, e à economia local. Os primeiros possuem baixo impacto sobre a absorção de mão de obra, que se concentra em setores de baixa produtividade, o que gera pressão reduzida sobre os salários, que tendem a ser determinados por condições locais de vida e não por sua produtividade. Assim, a renda doméstica se concentra entre os proprietários de capital dos setores dinâmicos. Estes setores, em geral, correspondem a uma faixa restrita de produtos primários, com reduzida diversificação horizontal, complementaridade setorial ou integração vertical. Dada a estreiteza da base produtiva, parcela substancial do consumo interno é importada.

Como parte deste processo, Prebisch (1949) evidencia, ainda, uma tendência de longo prazo de deterioração dos termos de troca como elemento marcante da divergência entre países centrais e periféricos. Este ponto atua como limitador ao crescimento e sujeita os países a processos de instabilidade recorrentes advindos de desequilíbrios do balanço de pagamentos, diante da redução progressiva de suas receitas externas.

Este diagnóstico é elemento central para a defesa da industrialização como fonte de redução das fontes do subdesenvolvimento, por meio da incorporação da mão de obra alocada em setores de baixa produtividade e a construção de elos setoriais. A ação deliberada do Estado, como elemento de estímulo, é percebida como essencial para o estímulo ao desenvolvimento, dada a magnitude da heterogeneidade estrutural prevalecente. Contudo, a simples mudança do eixo de desenvolvimento, em direção a um modelo voltado para dentro, pode não ser suficiente para alterar a condição heterogênea e especializada (Rodriguez, 2009; Bielchovschy, 2000). O processo de industrialização pode acentuar a vulnerabilidade externa, caso gere requisitos adicionais de importações em setores intermediários e de bens de capital, em magnitude superior às receitas de exportações. Adicionalmente, a incorporação exógena de técnicas originalmente adotadas nos países avançados pode gerar ineficiências decorrentes de processos produtivos dispendiosos e subaproveitadores do recurso abundante (Furtado, 1961; Tavares, 2011; Rodriguez, 2009). 
O debate sobre a industrialização e políticas de desenvolvimento tem sido ponto relevante também no debate promovido por autores da corrente neo-estruturalista. Embora sua base seja a visão estruturalista tradicional, esta visão busca incorporar de modo mais enfático elementos relacionados à promoção de inovações e à geração endógena de progresso técnico como elemento de superação de assimetrias; e o reconhecimento sobre a necessidade de políticas visando ao ajuste e ao equilíbrio macroeconômico de curto prazo, , num contexto pós crise da dívida externa nos países da América Latina e de crescimento de popularidade de políticas inspiradas no Consenso de Washington (Bielchovschy, 2000; Ffrench-Davis,1988, Sunkel e Zuleta, 1990; Fainzylber, 1993; Ocampo, 2011)

Em suma, o enfoque estruturalista parte do diagnóstico da condição subdesenvolvida como decorrente das relações econômicas interdependente, porém assimétrica, entre os países centrais e em desenvolvimento. A especialização das estruturas produtivas dos PEDs em setores de menor densidade tecnológica, cuja demanda depende dos ciclos nos países avançados, contribui para que estes possuam menor capacidade de geração endógena de progresso técnico, de redução de sua heterogeneidade estrutural e de seu grau de vulnerabilidade externa. Num contexto em que os modos de produção são altamente conectados internacionalmente, por meio de cadeias globais de valores, este argumento segue válido, à medida que as etapas de maior valor agregado permanecem concentradas nos centros de decisão das empresas internacionalmente ativas e o diferencial dos países de menor grau de desenvolvimento se concentra suas características de custos locacionais, em especial ligadas ao custo do trabalho, como descrito por Baldwin et al. (2014), Palley (2014) e por Arbache (2013).

\section{Condições de financiamento externo e ciclos reflexos}

A disponibilidade de fontes de financiamento externa é elemento fundamental para a sustentabilidade financeira de países deficitários em conta-corrente. De modo análogo à descrição de Minsky (1986), fluxos externos de capital permitem o alcance de taxas de crescimento superiores a uma situação equilibrada, embora tragam consigo fontes de fragilidade externa decorrentes de compromissos externos (Moreno-Brid, 2003; BarbosaFilho, 2001; Foley, 2001; Kregel, 2008; Wolfson, 2002; entre outros).

Algumas diferenças podem ser ressaltadas entre os dois tipos de avaliação (Amado e Resende, 2007; Santiago, 2016). Em primeiro lugar, enquanto na análise das relações de financiamento doméstico de uma economia, o fator gerador de fragilidade se associa com a conformação de compromissos financeiros e um grau crescente de endividamento, numa economia aberta há o problema adicional relacionado à sua capacidade de geração de divisas, vinculada a aspectos estruturais, como discutido na seção anterior. Em segundo lugar, relações econômicas internacionais envolvem transações em moeda estrangeira, fazendo com que os balanços das unidades envolvidas estejam expostos a descasamentos de moedas. Em terceiro lugar, diferentemente de uma economia fechada, em que os bancos atuam no mesmo ambiente de expectativas que as demais firmas, com uma relativa 
sincronia de impulsos entre devedor e credor, em economias abertas, os credores frequentemente são sensibilizados por fatores alheios aos países devedores, associados ao grau de aversão a riscos em suas matrizes (Prates, 2004; Akyüs, 2008).

O processo de liberalização e desregulamentação dos mercados financeiros nacionais, intensificado a partir da década de 1980 nos países avançados e de 1990 nos PEDs, teve efeito dinamizador destas características. Propiciaram maior liberdade de movimentos de capitais e interpenetração entre mercados (Cintra; Farhi, 2008). Do ponto de vista dos detentores de ativos, contribuiu para o aumento da capacidade de ingresso e de saída de operações envolvendo diferentes atividades financeiras e países, conforme a variação de seu grau de aversão a riscos.

Do ponto de vista dos países receptores de recursos, este ambiente propiciou uma dinâmica volátil e procíclica de seu acesso a fontes de financiamento externo. O maior acesso a recursos externos nos períodos de expansão, em geral em montante superior a suas posições deficitárias, contribui para a conformação de fragilidades advindas do aumento dos preços de ativos domésticos, do endividamento em moeda estrangeira e pela apreciação das taxas de câmbio. Diante de paradas súbitas dos fluxos, as perspectivas são de reversão deste quadro, propiciando condições de materialização de crises financeiras (Eichengreen et al., 2002; Prates, 2004; Akyüs, 2008). No caso dos PEDs, podem ser enfatizadas assimetrias prevalecentes nos sistemas monetário e financeiro internacionais, que contribuem para que haja maior suscetibilidade a períodos de instabilidade.

A assimetria no sistema monetário internacional pode ser associada a graus diferenciados de conversibilidade de moedas domésticas no plano internacional, em relação a suas capacidades de exercerem o papel de unidade de conta, meio de pagamento e de reserva de valor (Prates, 2004).

Apesar da característica que a moeda exerce no plano doméstico como unidade conservadora de liquidez, como discutido por Keynes (1936), deixam de possuir um valor em termos de si próprias quando são avaliadas transações entre diferentes países e moedas, passando a ser referenciadas em termos das outras moedas. O que garante liquidez a uma moeda é a confiança que lhe é atribuída sobre sua capacidade de conversão nas outras no momento futuro, sem perdas volumosas (Sardoni, 2013).

O dólar se configura no topo da pirâmide hierárquica das moedas, como instrumento de maior grau de liquidez global, em função do peso da economia dos EUA e de seu sistema financeiro (Braga; Cintra, 2004; Tavares, 1985; Tavares; Melin, 1997). As moedas dos PEDs possuem menor grau de conversibilidade e atributos como reserva de valor internacional (Prates, 2004). Estes países possuem maior dificuldade de emissão de instrumentos de dívida na própria moeda (Eichengreen et al., 2002). O grau de aceitação destas moedas tende a oscilar conforme o ambiente global de riscos. Momentos de exacerbação da incerteza nos sistemas financeiros globais contribuem para fugas em direção ao dólar ou às demais moedas dos países centrais (Prates, 2004). 
Da mesma forma que o sistema monetário, o sistema financeiro internacional se caracteriza por uma natureza assimétrica. Este fato pode ser evidenciado pela diferença de dimensão e complexidade dos sistemas financeiros atuantes entre os países; e pelos volumes de recursos negociados. No plano doméstico dos PEDs, nota-se relativa precariedade de seus sistemas financeiros, que reduz a capacidade do setor bancário em atuar plenamente como agente de financiamento, atendendo às demandas de crédito de longo prazo por parte do setor privado (Amado; Resende, 2007; BID, 2005). Adicionalmente, podem ser percebidas proporções diferenciadas dos fluxos de capitais entre países avançados e em desenvolvimento. A decisão sobre a alocação de recursos externos por parte das instituições financeiras internacionais se relaciona em parte a estratégias de diversificação de portfólio, estabelecidas em suas matrizes. Para os países receptores em desenvolvimento, entradas massivas de capital podem ter efeitos relevantes sobre os sistemas financeiros domésticos, principalmente nos países onde forem mais estreitos e pouco diversificados (Prates, 2004; Griffith-Jones, Kregel; Ocampo, 2007). When it rains it pours (Kaminsky; Reinhart; Végh, 2005).

Neste sentido, os modos de inserção comercial e financeiro dos PEDs na economia global se combinam, acentuando a fragilidade dos PEDs a crises financeiras. A predominância de estruturas produtivas de baixo valor teor tecnológico contribui para a geração de déficits recorrentes em conta-corrente, criando estruturas financeiras devedoras líquidas do ponto de vista externo. Dada a natureza volátil dos fluxos de capitais, o atendimento às necessidades de financiamento destes países tende a oscilar conforme as ondas de otimismo e pessimismo global. Esta característica cria um elemento reflexo dos ciclos nos países em desenvolvimento, em relação aos ciclos dos países avançados, nos moldes discutidos por Amado e Resende (2007).

Do ponto de vista do Estado, estas assimetrias geram obstáculos para que exerça seu papel anticíclico, limitando sua capacidade de atuar como big government e big bank. $\mathrm{O}$ reduzido grau de comando sobre as entradas e saídas de capitais externos gera uma tendência a que as políticas macroeconômicas tenham um tom procíclico. A relativa abundância de fontes externas de financiamento nos períodos de boom gera espaço para maior grau de endividamento e menores pressões sobre as ações de política monetária, ocorrendo o oposto nos períodos de menor dinamismo externo (Ocampo, 2011). A atuação dos órgãos multilaterais, como o Fundo Monetário Internacional (FMI), acentua esta característica.

\section{Relações financeiras intersetoriais e mecanismos de incentivo procíclicos}

As relações financeiras entre as unidades econômicas é elemento central na hipótese de fragilidade financeira de Minsky. A evolução da alavancagem de credores e devedores, imersos no mesmo contexto de expectativas e movidos por expectativas de lucros, favorece a elevação dos investimentos, da mesma forma que pode criar vulnerabilidades a oscilações das condições financeiras. Uma possível forma de abordar 
este ponto é por meio de um enfoque contábil. Os quadros 1 e 2 mostram respectivamente e de modo estilizado, o balanço e os fluxos intersetoriais de uma economia aberta devedora em relação ao resto do mundo, dividida famílias, firmas, bancos, governo e banco central, além do setor "mundo", correspondente à contrapartida das relações com o exterior.

A intenção desta seção é, a partir do desenho de relações de interdependência setoriais principais, traçar elementos que contribuam para a compreensão sobre a evolução da vulnerabilidade de uma economia ao longo dos ciclos. Não é a intenção desta seção, o desenvolvimento de um modelo de consistência entre fluxos e estoques, por meio do estabelecimento de funções de comportamento dos setores e de simulações sobre a evolução dinâmica das variáveis, nos moldes das contribuições de Godley e Lavoie (2007), Santos e Zezza (2005) e Nikiforos e Zezza (2017).

\subsection{Famílias}

As famílias são apresentadas de modo simplificado no esquema dos quadros 1 e 2 . Sua renda é composta por recebimentos de salários, juros e dividendos. A posse de ações confere a seus detentores, adicionalmente, ganhos de capital, que embora contribuam para a variação patrimonial, não constituem rendimentos. As famílias pagam impostos ao governo numa proporção de sua renda. Assume-se por simplificação que somente este setor paga impostos. Adicionalmente, consomem produtos e serviços produzidos localmente ou importados, numa proporção estável de sua renda, nos moldes discutidos por Keynes (1936).

É prevista a alocação da parcela não consumida da renda em duas alternativas: depósitos bancários e ações. Como elemento simplificador, é assumido que somente as famílias detém ações, e que sua oferta é fixa. Deste modo, as compras e vendas destes instrumentos se compensam a cada período e novos fluxos de renda se direcionam de forma integral a novos depósitos. O que oscila a cada período é a intensidade das negociações e sua direção, com efeitos sobre seus preços. Famílias podem ser separadas analiticamente entre trabalhadores e proprietários de riqueza. A renda dos trabalhadores corresponde a salários, e dos proprietários de riqueza a juros provenientes de depósitos bancários e dividendos sobre ações corporativas. A posse de ações confere a seus detentores, adicionalmente, ganhos de capital, que embora contribuam para a variação patrimonial, não constituem rendimentos. 
Quadro 1

Balanço de uma economia aberta devedora, desagregada por setores.

\begin{tabular}{|l|c|c|c|c|c}
\hline & Famílias & Firmas & Bancos & Governo & Banco Central \\
\hline Depósitos & $+D$ & - & $-D$ & - & - \\
\hline Reservas no BC & - & - & $+H_{b}$ & $+H_{g}$ & $-H$ \\
\hline Títulos públicos & - & - & $+B_{b}$ & $-B$ & $+B_{b c}$ \\
\hline Res. Internacionais & - & - & - & - & $F X . X R$ \\
\hline Ações & $+P_{E} \cdot E$ & - & - & - & - \\
\hline Ágio & - & $+G W_{f}$ & $+G W_{b}$ & - & - \\
\hline Crédito doméstico & - & $-L$ & $+L$ & - & - \\
\hline Crédito externo & - & $-F X . X L_{f}$ & $-F X . X L_{b}$ & $-F X . X L_{g}$ & - \\
\hline Suporte de liquidez & - & - & $-R D$ & - & $+R D$ \\
\hline Ativos de capital & - & $+P_{K} \cdot K$ & - & - & - \\
\hline Patrimônio Líquido & $-N W_{h}$ & $-P_{E} \cdot E_{F}$ & $-P_{E} \cdot E_{B}$ & $-N W_{g}$ & $-N W_{b c}$ \\
\hline Soma & - & - & - & - & - \\
\hline
\end{tabular}

\begin{tabular}{c|c|c|}
\hline $\begin{array}{c}\text { Consolidado } \\
\text { País }\end{array}$ & Mundo & Total \\
\hline- & - & - \\
\hline- & - & - \\
\hline- & - & - \\
\hline$F X . X R$ & $-F X . X R$ & - \\
\hline- & - & - \\
\hline$+G W$ & - & $+G W$ \\
\hline- & - & - \\
\hline$-F X . X L$ & $+F X . X L$ & - \\
\hline- & - & - \\
\hline$+P_{K} \cdot K$ & - & $+P_{K} \cdot K$ \\
\hline$-P_{E} \cdot E+F X(X R-X L)$ & $-N W x$ & $-P_{K} \cdot K-G W$ \\
\hline- & - & - \\
\hline
\end{tabular}

Nota: Sinal positivo (+) corresponde a ativos. Sinal negativo (-) saldos do passivo e do patrimônio líquido.

Legenda:

$D=$ depósitos; $H=$ base monetária; $B=$ títulos públicos; $P_{e}=$ preço das ações; $E=$ estoque de ações; $N W=$ patrimônio líquido; $G W=$ ágio de valor das ações sobre valor patrimonial; $R=$ reservas junto ao banco central; $L=$ crédito doméstico; $R D=$ linhas de suporte de liquidez do banco central ao sistema bancário; $F X=$ taxa de câmbio; $X L=$ crédito externo; $K=$ estoque de capital; $X R=$ reservas internacionais. Os subscritos h, f, b, g, bc e x indicam respectivamente famílias, firmas, bancos, governo, banco central e resto do mundo.

Fonte: Elaboração própria 
Quadro 2

Fluxos intersetoriais estilizados de uma economia aberta devedora, desagregada por setores

\begin{tabular}{|c|c|c|c|c|c|c|c|c|}
\hline & Famílias & Firmas & Bancos & Governo & Banco Central & $\begin{array}{l}\text { Consolidado } \\
\text { País }\end{array}$ & Mundo & Total \\
\hline Oferta global & - & $+Y_{c}+Y_{k}$ & - & - & - & $+Y_{c}+Y_{k}$ & $+F X . I M$ & $+Y_{c}+Y_{k}+F X . I M$ \\
\hline Consumo & $-C$ & - & - & $-G$ & - & $-C-G$ & $-F X . E X$ & $-C-G-F X . E X$ \\
\hline Renda & $+W+$ Div & $-W-D i v$ & - & & - & - & - & - \\
\hline Impostos & $-T$ & & - & $+T$ & - & - & - & - \\
\hline Saldo (1) & $+S_{h}^{\prime}$ & $+L O_{f}$ & 0 & $+S P$ & 0 & $+S_{p}^{\prime}+S_{g}^{\prime}$ & $+S_{x}^{\prime}$ & $+S_{p}^{\prime}+S_{g}^{\prime}+S_{x}^{\prime}$ \\
\hline Juros Tesouro & - & - & $+i_{B} \cdot B_{b}^{-1}$ & $-i_{B} \cdot B^{-1}$ & $+i_{B} \cdot B_{b c}^{-1}$ & - & - & - \\
\hline Juros Depósitos & $+i_{D} \cdot D^{-1}$ & - & $-i_{d} \cdot D^{-1}$ & - & - & - & - & - \\
\hline Juros Crédito & - & $-i_{L} \cdot L^{-1}$ & $+i_{L} \cdot L^{-1}$ & - & - & - & - & - \\
\hline Juros suporte liquidez & - & - & $-i_{R D} \cdot R D^{-1}$ & - & $+i_{R D} \cdot R D^{-1}$ & & & - \\
\hline Juros crédito externo & - & $-i_{X L} \cdot F X . X L$ & $-i_{X L} \cdot F X . X L_{b}^{-1}$ & $-i_{X L} \cdot F X . X L_{g}^{-}$ & - & $-i_{X L} \cdot F X . X L^{-1}$ & $+i_{X L} \cdot F X \cdot X L^{-1}$ & - \\
\hline Juros reservas & - & -2 & - & - & $+i_{X R} \cdot F X \cdot X R^{-1}$ & $+i_{X R} \cdot F X . X R^{-1}$ & $-i_{X R} \cdot F X . X R^{-1}$ & - \\
\hline Dist. Lucros BC & - & - & - & $+D R_{b c}$ & $-D R_{b c}$ & & & - \\
\hline Saldo (2) & $+S_{h}$ & $+S_{f}$ & $+S_{h}$ & $+S_{a}$ & 0 & $+S_{n}+S_{a}$ & $+S_{x}$ & $+S_{n}+S_{a}+S_{x}$ \\
\hline Operações em default & - & - & $-D E F$ & - & - & $+D E F$ & - & - \\
\hline Depósitos & $-\Delta D$ & - & $+\Delta D$ & - & - & - & - & - \\
\hline Reservas no BC & - & - & $-\Delta H_{b}$ & $-\Delta H_{g}$ & $+\Delta H$ & - & - & - \\
\hline Gastos de capital & - & $-I$ & - & - & - & $-I$ & - & $-I$ \\
\hline Crédito & - & $+\Delta L$ & $-\Delta L+D E F$ & - & - & - & - & - \\
\hline Suporte de liquidez & - & - & $+\Delta R D$ & - & $-\Delta R D$ & - & - & - \\
\hline Financiamento externo & - & $+F X . \Delta X L_{f}$ & $+F X . \Delta X L_{b}$ & $+F X . \Delta X L_{g}$ & - & $+F X . \Delta X L$ & $-F X . \Delta X L$ & - \\
\hline Reservas internacionais & - & - & - & & $-F X . \Delta X R$ & $-F X . \Delta X R$ & $+F X . \Delta X R$ & - \\
\hline Títulos públicos & - & - & $-\Delta B_{b}$ & $+\Delta B$ & $-\Delta B_{b c}$ & - & - & - \\
\hline Saldo (3) & - & - & - & - & - & - & - & - \\
\hline
\end{tabular}

Legenda: $Y_{c}=$ produção de bens de consumo; $Y_{k}=$ produção de ativos de capital; $F X=$ taxa de câmbio; $I M=$ importações; $E X=$ exportações; $C=$ consumo; $G=$ gastos do governo; $I=$ gastos de capital; $W=$ salários; $D i v=$ dividendos distribuídos; $T=$ impostos; $S^{\prime}{ }_{h}=$ poupança bruta das famílias; $L O_{f}=$ resultado operacional das firmas; $S P=$ superávit primário do governo; $S^{\prime}{ }_{x}=$ déficit comercial; $i_{B}=$ juros sobre títulos públicos; $i_{D}=$ juros sobre depósitos; $i_{L}=$ juros sobre empréstimos; $i_{R D}=$ juros sobre linhas de suporte de liquidez do banco central ao sistema bancário; $i_{X L}=$ juros sobre fluxos externos de capital; $i_{X R}=$ juros sobre reservas internacionais; $S_{h}=$ poupança líquida das famílias; $S_{f}=$ resultado líquido das firmas; $S_{b}=$ resultado líquido dos bancos; $S_{g}=$ saldo fiscal nominal; $S_{\mathrm{x}}=$ déficit de conta-corrente; $D E F=$ operações de crédito em default O símbolo $\Delta$ indica variação em relação ao período imediatamente anterior. Os subscritos $h, f, b, g, b c$ e $x$ indicam respectivamente famílias, firmas, bancos, governo, banco central e resto do mundo. $\mathrm{O}$ sobrescrito $(-1)$ indica período anterior.

Fonte: Elaboração própria 


\subsection{Firmas}

$\mathrm{O}$ balanço das firmas é composto no lado do ativo pelo estoque de capital $\left(P_{K} \cdot K\right)$, cujo preço $\left(P_{K}\right)$ oscila conforme as expectativas de receitas ao longo de sua vida útil. Os passivos são compostos por dívidas contraídas junto aos bancos $(L)$, em moeda doméstica, e por captações externas $\left(X L_{f}\right)$, contratadas em moeda estrangeira $(F X)$. Não é considerada a manutenção de estoques de produtos entre períodos. $O$ valor econômico $\left(V E_{f}\right)$ pode ser definido como a diferença entre o estoque de capital e o total dos passivos. O estoque de ações emitidas $\left(P_{E} \cdot E_{f}\right)$ equivale ao patrimônio líquido, refletindo a percepção do mercado sobre o valor da firma ${ }^{3}$. Este tratamento pode gerar uma divergência entre $P_{E} . E_{f}$ e $V E_{f}$, que é evidenciado na forma de um ágio $(G W)$, registrado no ativo ${ }^{4}$, que pode ser interpretado de modo semelhante ao $q$ de Tobin (1969). A expressão (1) ilustra o argumento:

$$
G W=P e . E_{f}-V E_{f} ; \quad \mathrm{q}=P e . E_{f} / V E_{f}
$$

As firmas produzem bens de consumo e de capital. A produção de bens de consumo pode ser vendida localmente às famílias ou exportada. Os bens de capital se destinam totalmente ao comércio doméstico intra-firmas. Os custos de produção se resumem ao pagamento de salários $(W)$. Parcela dos lucros é paga aos acionistas na forma de dividendos (Div). A parte residual é retida, correspondente ao resultado operacional $\left(\mathrm{LO}_{f}\right)$.

Os níveis de alavancagem considerados ideais oscilam conforme a percepção de riscos (Minsky, 1986). A expressão (2) evidencia o índice de alavancagem das firmas, como a relação entre o passivo e o capital próprio. Sua taxa de variação entre períodos pode ser identificada por $(3)^{5}$ :

$$
\begin{aligned}
& L E V_{f}=\left(P S V_{f}\right) / P_{e} . E_{f} ; \quad P S V_{f}=L+F X . X L_{f} \\
& l e v_{f}=p s v-p_{e}=\lambda . l+(1-\lambda) \cdot\left(f x+x l_{f}\right)-p_{e}
\end{aligned}
$$

Como ilustrado em (3), o indicador de alavancagem depende positivamente da variação dos passivos e negativamente da variação do preço das ações. Uma situação de boom, em que haja movimento de alta do crédito e dos mercados de ações, pode resultar na redução do nível de alavancagem, caso $p_{e}>p s v$. Da mesma forma, fases de descenso podem gerar elevação do indicador, ainda que as firmas contraiam de seu nível de atividade e de endividamento, caso $p_{e}<p s v$. Considerando que os mercados de capitais potencialmente respondem mais rápido a mudanças nas expectativas, o preço das ações pode atuar de modo antecipador sobre a variação na estrutura financeira das firmas,

(3) Alternativamente, esta rubrica poderia ser considerada como uma obrigação das firmas em relação aos acionistas Godley e Lavoie (2007) definem das ações como parte do passivo das firmas. Contudo, uma desvantagem deste expediente é a perda de significado do patrimônio líquido, que aparece como resíduo, podendo ser negativo em situações em que o preço das ações supera o valor econômico das firmas $(q>1)$.

(4) O valor total das ações pode não coincidir necessariamente com uma noção de preço justo ou de fundamentos. Num cenário de conhecimento imperfeito, em que os comportamentos e tempos de resposta dos agentes são diferentes nos diversos mercados, e no qual as expectativas são baseadas em convenções, nos moldes discutidos por Keynes (1936, 1937), não há um componente necessário que garanta o market clearing (Aglietta, 2004). A dinâmica dos mercados financeiros contribui para descolamentos entre os preços, elevando relativamente os preços das ações nas fases de euforia (q>1) e deprimindo-os nas fases de contração $(\mathrm{q}<1)$.

(5) Onde $\lambda=L / P S V_{f}$ e letras minúsculas indicam variação percentual entre dois períodos. 
estimulando a formação de novas posições especulativas nas fases de crescimento, ou forçando ajustes de desalavancagem nos períodos de retração.

Outro fator relevante no caso de economias abertas é a taxa de câmbio. Depreciações podem deteriorar a estrutura financeira, mesmo na ausência de novas contratações de dívida ou variações nos preços das ações. Um fato recorrente nos $P E D s$ tem sido uma trajetória procíclica da taxa de câmbio, sujeitando as economias a descasamentos de moedas, como reportado por Eichengreen et al (2002). Nas situações em que isto ocorre, há um elemento de reforço para a dinâmica instável em economias dependentes de crédito em moeda estrangeira.

A demanda por fontes de crédito internacionais nos países nos PEDs pode, em grande parte, ser atribuída ao desenvolvimento precário de seus sistemas financeiros domésticos, e à baixa capacidade de atendimento das demandas por parte do setor privado (Amado; Resende, 2007). Sobre este ponto, BID (2005) ilustra características do sistema financeiro dos países em desenvolvimento.

A complexidade acentuada dos condicionantes para a instabilidade financeira em economias abertas pode ser retratada também a partir da análise de usos e fontes das firmas. Este ponto pode ser percebido pelas expressões (4) e (5), baseadas numa visão prospectiva a partir do Quadro 2.

$$
\begin{aligned}
& I^{+1}=S_{f}^{+1}+\Delta L^{+1}+\Delta X L^{+1} \cdot F X^{+1} \\
& S_{f}^{+1}=L O_{f}^{+1}-i_{L} \cdot L-i_{X} \cdot F X . X L
\end{aligned}
$$

A expressão (4) identifica os mecanismos possíveis de financiamento das atividades das firmas. A expressão (5) ilustra a relação entre o serviço financeiro da dívida e o resultado líquido das firmas. Numa posição financeira hedge, os investimentos (ou gastos de capital) são financiados a partir de recursos próprios $\left(S_{f}^{+1} \geq I^{+1}\right)$, e o serviço da dívida é não positivo $\left(i_{L} \cdot L+i_{X} \cdot F X \cdot X L<=0\right)$, contribuindo para uma necessidade de financiamento negativa $\left(\triangle P S V_{f}^{+1} \leq 0\right)$. Numa situação especulativa, a firma espera resultados líquidos não negativos $\left(S_{f}^{+1} \geq 0\right)$, porém em montante menor que os gastos de capital $\left(S_{f}^{+1}<I^{+1}\right)$, demandando recursos externos para seu financiamento $\left(\triangle P S V_{f}^{+1}>\right.$ $0)$. Numa posição Ponzi, os resultados esperados pela firma são negativos $\left(S_{f}^{+1}<0\right)$, denotando a necessidade de alienação de ativos ou de ampliação do grau de endividamento para minimamente honrar os compromissos previamente assumidos.

O uso de crédito para o financiamento de novos investimentos tende a ser estimulado enquanto a expectativa de lucros for superior à dos encargos financeiros. Uma possível condição de vulnerabilidade financeira, dentro de um cenário em que prevalecem estruturas especulativas, pode estar mascarada pelo estado de expectativas favoráveis, que se refletem nos preços dos ativos. Num contexto de economia aberta, a fragilidade financeira das firmas é influenciada também pela evolução das taxas de juros sobre os passivos externos, que por sua vez, depende das taxas de juros externas e do spread de risco associado ao país, e pela taxa de câmbio. 


\subsection{Bancos}

Os bancos, de modo estilizado, concedem empréstimos às firmas e adquirem títulos do governo, do lado de seus ativos; e captam depósitos, no lado dos passivos. Numa economia aberta, há a possibilidade de captarem recursos do exterior. Seus resultados decorrem do diferencial de juros entre suas operações (Freixas; Rochet, 2008). É feita a suposição simplificadora de que não incorrem em custos operacionais, como despesas administrativas e salários, e que reinvestem totalmente seu lucro, como na análise de Le Heron e Mouakil (2007). Da mesma forma que as firmas, seu patrimônio líquido corresponde ao valor de suas ações negociadas no mercado secundário. A diferença entre o valor total das ações e seu valor econômico gera um ágio no lado dos ativos $\left(G W_{b}\right)$.

O banco central regula a atuação dos bancos, por meio de diferentes mecanismos. Exige reservas obrigatórias líquidas, como proporção dos depósitos, com vistas a limitar a expansão dos ativos de crédito $\left(\Lambda_{1} . D\right)$. Influencia a oferta de moeda por meio da base monetária $\left(H_{b}\right)$. Como parte de suas funções de banco dos bancos e emprestador de última instância, disponibiliza ao setor bancário linhas de suporte de liquidez $(R D)$. Adicionalmente, pode atuar com a imposição de limites prudenciais e regras de supervisão e de conduta sobre as operações bancárias (Freitas, 2008). Os bancos podem constituir ativos imediatamente líquidos, que no esquema apresentado se direcionam a reservas voluntárias junto ao banco central $\left(\Lambda_{2} . D\right)$, cujo montante tende a oscilar conforme seu grau de preferência pela liquidez, contribuindo para reduzir a influência das autoridades sobre a oferta monetária. Este fato é reforçado pela capacidade dos bancos de adotar práticas de inovações financeiras em suas captações domésticas, como destacado por Minsky (1986) e Freitas (1997), ou de captar recursos no exterior. A expressão (6) identifica a relação entre os depósitos e a base monetária:

$$
H_{b}=\left(\Lambda_{1}+\Lambda_{1}\right) \cdot D
$$

O nível de alavancagem bancária e sua taxa de variação podem ser expressos pelas expressões (7) e (8), como a relação entre seu passivo e patrimônio líquido ${ }^{6}$. Sua evolução depende positivamente da evolução dos saldos de passivo e negativamente do preço das ações. Da mesma forma que as firmas, em cenários cíclicos expansivos, processos de valorização dos mercados acionários podem contribuir para a redução da alavancagem, caso a taxa de crescimento dos preços das ações seja superior à taxa de crescimento dos passivos.

$$
\begin{aligned}
& L E V_{b}=\frac{P S V_{b}}{P_{E} \cdot E_{b}}=\frac{D+F X \cdot X L_{b}+R D}{P_{E} \cdot E_{b}} ; \quad ; \quad P S V_{b}=D+F X \cdot X L_{b}+R D \\
& l e v_{b}=d \cdot \varsigma_{1}+\varsigma_{2} \cdot\left(f x+x l_{b}\right)+\left(1-\varsigma_{1}-\varsigma_{2}\right) \cdot R D-p_{e} ;
\end{aligned}
$$

Considerando $R D$ imaterial em condições de tranquilidade; numa economia fechada, a evolução do passivo bancário está diretamente ligada ao nível de atividade. Em economias abertas, o acesso a recursos no exterior amplia a capacidade de expansão dos ativos. Entretanto, depreciações da taxa de câmbio podem se refletir em aumento da

(6) Onde $\varsigma_{1}=D /\left(P S V_{b}\right), \varsigma_{2}=F X . X L_{b} /\left(P S V_{b}\right)$, e letras minúsculas indicam variação percentual da variável em relação ao período anterior 
alavancagem, mesmo que não haja oscilações do nível de atividade. Da mesma forma que o discutido para as firmas, o comportamento procíclico da taxa de câmbio e dos preços das ações pode elevar a vulnerabilidade dos bancos a reversões de cenário, à medida que estimulam o aumento das atividades nas fases de crescimento e o encerramento de posições em fases de descenso.

O incentivo para novas operações de crédito depende da expectativa de lucros. Este ponto pode ser compreendido a partir da decisão microeconômica de uma firma bancária, de modo similar ao descrito por Freixas e Rochet (2008), a partir do spread entre operações ativas e passivas, ajustado pela probabilidade esperada de default (PD), como exposto em (9), assumindo a inexistência de garantias associadas às operações.

$$
S_{b(a)}^{t+1}=\left(1-P D^{+1}\right) \cdot i_{L} \cdot L+i_{B} \cdot B_{b}-i_{D} \cdot D-i_{X L} \cdot F X \cdot X L_{b}-i_{R D} \cdot R D
$$

Num cenário de expectativas convencionais, a definição de $P D^{+1}$ pode ser vista como baseada em eventos passados e sujeita a erros de estimativa ex post. Variações em relação ao esperado podem reforçar ou gerar um processo de ajuste de projeções passadas. A expressão (10) evidencia a relação entre usos e fontes por parte dos bancos entre os períodos $t$ e $t+1$, evidenciando os mecanismos de financiamento de sua atividade de crédito e que condicionam sua situação financeira.

$$
\left(\Delta L^{+1}-D E F^{+1}\right)+\Delta B_{b}^{+1}=S_{b(a)}^{t+1}+\left(\Delta D^{+1}-\Delta H_{b}^{+1}\right)+F X^{+1} \cdot \Delta X L_{b}^{+1}+\Delta R D^{+1}
$$

Os bancos são entidades especulativas por natureza. Utilizam recursos externos captados junto a outros setores como funding para novas concessões de empréstimos. São inerentemente suscetíveis a variações nas condições financeiras ou na performance da carteira de empréstimos que afetem sua rentabilidade. Lucros negativos por períodos continuados geram situações Ponzi, podendo exigir a contração de suas operações ativas ou o acréscimo de captações com a finalidade de cobrir os compromissos. Da mesma forma que o descrito para as firmas, pode ser definido um componente procíclico na atividade bancária.

Considerando que variações dos saldos de títulos públicos tenham como contrapartida um aumento dos depósitos, e que seu risco de default seja desprezível (Sardoni 2013), $\Delta B$ acarreta efeitos limitados sobre a condição financeira dos bancos. Por outro lado, novas operações de empréstimos $(\Delta L)$ dependem da expectativa de lucros. A projeção de aumento da probabilidade de default pode ensejar spreads esperados negativos, configurando situações Ponzi. Em economias abertas, há a adição de dois elementos de vulnerabilidade, associados às taxas de juros sobre as captações externas e à taxa de câmbio.

\subsection{Governo e banco central}

O Estado possui objetivos de atuação diferenciados em relação ao setor privado. Sua orientação visa à manutenção dos níveis de emprego e de renda em níveis considerados adequados. Partindo de uma conceituação tipicamente keynesiana, os gastos públicos devem ser vistos em relação à sua capacidade de geração de renda e de demanda efetiva. Neste sentido, sua ação é eminentemente anticíclica. 
Numa situação de ociosidade de recursos, os gastos do governo são geradores de renda e o aumento de seus passivos contribui para aumentar a liquidez da economia (Sardoni, 2013). Num contexto de economia aberta, a capacidade do Estado de impor condição soberana sobre sua dívida somente é válida se o instrumento de dívida não contempla a promessa de sua conversão em outro ativo ou moeda (Sardoni, 2013). Se o Estado se endivida em moeda estrangeira, sua capacidade de pagamento depende de sua capacidade da conversão de sua dívida no prazo combinado. O montante total da dívida e as obrigações financeiras em moeda estrangeira criam suscetibilidade à falta de capacidade de honrar compromissos externos ou falta de confiança sobre sua capacidade por parte de detentores de seus passivos.

No esquema apresentado nos quadros 1 e 2, o governo arrecada impostos das famílias e seus gastos do governo são compostos integralmente por bens de consumo. Os déficits fiscais são financiados por emissão de títulos públicos, que podem ser adquiridos pelo sistema bancário ou pelo banco central.

O banco central possui um leque amplo de atividades sob seu escopo. Pode exigir junto aos bancos a manutenção de encaixes mínimos em relação ao montante de depósitos $\left(\Lambda_{1} . H_{b}\right)$, conceder mecanismos de liquidez ao sistema bancário $(R D)$ ou demandar níveis mínimos de capital. Ao utilizar as taxas de juros como instrumento de política monetária, compra e vende títulos públicos de sua carteira junto ao sistema bancário. Adicionalmente, mantém reservas em moeda estrangeira, que podem ser utilizadas com fins prudenciais ou como forma de gerenciamento da taxa de câmbio. É considerada a distribuição dos resultados ao governo ao fim de cada período, sendo incorporados ao saldo fiscal $\left(D R_{b c}\right)$.

O balanço consolidado do governo e do banco central é expresso em (11):

$$
N W_{g+b c}=H_{b}+F X . X R+R D-B_{b}-F X . X L_{g}
$$

A dívida consolidada líquida do governo e banco central $\left(D L_{g ; b c}\right)$, pode ser expressa pela diferença entre o total dos passivos e os ativos financeiros dos dois setores (Barbosa-Filho, 2014). Pelo balanço da Quadro 1, corresponde à soma dos títulos públicos domésticos em poder do setor privado; captações em moeda estrangeira e base monetária; subtraídos das reservas em moeda estrangeira detidas pelo Banco Central, como na expressão (12).

$$
D L_{g ; b c}=B_{h}+F X .\left(X L_{g}-X R\right)+H_{b}-R D
$$

Colocando a expressão (11) em termos de variação entre os períodos $t$ e $t+1$, e substituindo os termos "abaixo da linha" do Quadro 2 por sua composição "acima da linha", tem-se que: $X R)$

$$
\Delta D L_{g+b c}^{+1}=-S P_{g}^{t+1}+i_{b} \cdot B_{h}+F X \cdot\left(i_{X L} \cdot X L_{g}-i_{x r} \cdot X R\right)-i_{R D} \cdot R D+\Delta F X^{+1} \cdot(X L-
$$

Normalizando $D L_{g ; b c}$ em relação ao PIB e calculando sua variação percentual em (13):

$$
\frac{\Delta\left(D L_{g+b c} / Y\right)^{+1}}{D L_{g+b c} / Y}=-\overline{\overline{s p}}_{g}^{t+1}+\varphi_{1} \cdot i_{B}+\varphi_{2} \cdot i_{X L}-\varphi_{3} \cdot i_{X R}+\left(\varphi_{2}-\varphi_{3}\right) \cdot g_{F X}-\varphi_{4} \cdot i_{D R}-
$$


Onde $\overline{\overline{S p}}_{g}^{t+1}=\frac{S P^{t+1}}{D L_{g+b c}} ; \varphi_{1}=\frac{B}{D L_{g+b c}} ; \varphi_{2}=\frac{F X . X L}{D L_{g+b c}} ; \varphi_{3}=\frac{F X . X R}{D L_{g+b c}} ; \varphi_{4}=\frac{R D}{D L_{g+b c}} ; g_{X R}=\frac{\Delta X R^{+1}}{X R} ;$ e $g_{Y}=\frac{\Delta Y^{+1}}{Y}$.

Trajetórias crescentes da dívida líquida são um indicativo de aumento da vulnerabilidade e de possíveis dificuldades em honrar compromissos futuros ou de refinanciar de posições vincendas. A expressão (14) evidencia quatro fatores principais que influenciam evoluções crescentes da dívida líquida em relação ao PIB: geração de déficits fiscais primários $\left(S P_{g}^{t+1}<0\right)$, as taxas de juros incidentes sobre os saldos passivos, depreciações da taxa de câmbio $\left(g_{F X}\right)$, e de modo negativo, a taxa de crescimento do nível de renda da economia $\left(g_{Y}\right)$.

Seguindo o referencial de Minsky (1986), algumas hipóteses podem ser construídas sobre a expressão (14). Uma estrutura tipicamente hedge pode ser observada quando há a expectativa de geração de saldos primários não negativos recorrentes pelo governo $\left(S P_{g}^{t+1} \geq 0\right)$, e na qual a posição líquida inicial é não devedora $\left(D L_{g ; b c} \leq 0\right)$. Neste sentido, os saldos fiscais nominais esperados $\left(S_{g}^{t+1}\right)$ são também não negativos. A alteração da capacidade do governo em honrar compromissos financeiros depende dos fluxos de superávits primários. Considerando a identidade entre as capacidades de financiamento dos setores, expressa em (15), do ponto de vista da economia consolidada, uma condição hedge implica em uma posição credora líquida negativa externa $\left(S_{x}^{t+1} \leq 0\right)$, típica de países export led, uma situação devedora do setor privado $\left(S_{p}^{t+1}-I^{t+1} \leq 0\right)$ ou uma combinação de ambos.

$$
S_{g}=-S_{x}-\left(S_{p}-I\right)
$$

Uma condição especulativa pode ser expressa por uma situação em que saldo fiscal primário pode ser tanto positivo quanto negativo. O que determina a condição financeira é a expectativa de trajetória não explosiva da dívida em relação à renda $\left(\frac{\Delta\left(D L_{g}+b c / Y\right)}{D L_{g+b c} / Y} \leq 0\right)$, como expresso em (16), a partir de (14).

$$
-\overline{\overline{s p}}_{g}^{t+1}+i_{D L, g+b c}+\left(\varphi_{2}-\varphi_{3}\right) g_{F X} \leq g_{y}
$$

Situações em que a expressão (16) não é satisfeita suscitam processos Ponzi. Nesta condição, há a expectativa de incapacidade de os gastos públicos atuarem como elemento dinamizador da renda doméstica, dentro de uma trajetória não explosiva da dívida pública, suscitando maior grau de desconfiança dos credores sobre a capacidade do governo em rolar compromissos vincendos ou financiar os déficits correntes.

Embora saldos fiscais positivos possam contribuir para uma dinâmica controlável da dívida pública, não são um fim em si mesmo. Numa perspectiva keynesiana, a posição fiscal se vincula diretamente com os objetivos de manutenção da renda em níveis adequados. Em situações de deficiência de capacidade de geração de demanda efetiva por parte do setor privado, uma atuação especulativa por parte do governo é plenamente justificável diante de seus objetivos.

Por outro lado, a expressão (16) evidencia um condicionante procíclico para a sustentabilidade da dívida pública, em relação às oscilações do nível de renda. Este fator 
tende a ser estimulado pela lógica circular entre gastos do governo e renda, tanto maior quanto mais elevado o multiplicador de gastos públicos. Períodos de maior dinamismo econômico podem contribuir para que a dívida pública líquida caia em níveis relativos, mesmo com a elevação em termos absolutos. Somado a este fator, a própria relação dívida/PIB considerada adequada pode oscilar conforme o estágio cíclico. Períodos de maior dinamismo econômico e intensidade dos fluxos externos de capital podem contribuir para uma maior aquiescência por parte dos investidores externos em relação à dívida pública, ao contrário de períodos de reversão cíclica, nos quais tende a imperar um nível mais alto de conservadorismo por parte dos agentes credores. Um nível de endividamento considerado adequado em determinado momento pode mostrar-se inadequado ex post (Minsky, 1986).

Há, neste sentido, um fator que concede maior flexibilidade para que o governo aumente seus gastos nos períodos de auge, atuando em reforço à dinâmica de aumento dos gastos e tomada de posições arriscadas por parte do setor privado. Nas fases de descenso, quando seria de se esperar uma atuação mais assertiva por parte do governo e amortecimento da queda do nível geral de renda, há a tendência de perda do vigor fiscal do governo numa economia aberta e devedora, seja por causa dos efeitos da contração econômica sobre a relação dívida/PIB, seja pela maior aversão a riscos por parte dos credores externos. Em situações em que a proporção de dívida em moeda estrangeira é mais alta, este fato se acentua.

A manutenção de taxas de crescimento elevadas e sustentáveis é um fator que contribui positivamente para a sustentabilidade da dívida pública. Contudo, num contexto de economias abertas e dependentes de fluxos de dívida em moeda externa, são evidentes limitações ao acúmulo de posições devedoras além de limites estabelecidos por características estruturais das economias, que podem ser fonte de vulnerabilidade durante ciclos de baixo crescimento e de deterioração das condições financeiras externas.

\subsection{Análise consolidada}

A consolidação da economia é construída pela soma dos saldos domésticos, deduzindo as relações intersetoriais. O resultado líquido das transações com o exterior, apresentado no Quadro 2, corresponde ao saldo de déficit de conta-corrente $\left(S_{x}\right)$, apresentado de modo estilizado, como a soma do saldo comercial de bens e serviços $\left(-S_{x}^{\prime}=F X .(E X-I M)\right)$, e dos fluxos de juros líquidos $\left(F X .\left(i_{X R} \cdot X R-i_{X L} \cdot X L\right)\right)$. Os fluxos de capital e o serviço de juros correspondente são evidenciados de forma líquida, pela diferença entre entradas e saídas, e não são discriminados em relação a modalidades, de modo simplificado ${ }^{7}$.

A dívida externa líquida do país pode ser expressa pela diferença entre o total de passivos e ativos financeiros externos, como em (17). A variação entre os períodos $t$ e $t+1$ é ilustrada em (18):

(7) Não se perde de vista, porém, de que há claras diferenciações em relação a formas de rendimento, graus de estabilidade e impulsos, como percebido por Griffth-Jones, Kregel e Ocampo (2007). O intuito limitado é avaliar a as exposições líquidas a que um país está sujeito. 


$$
\begin{aligned}
& D X L=F X .(X L-X R) \\
& \frac{\Delta(D X L / Y)}{(D X L / Y)}=\overline{\bar{s}}_{x}^{\prime t+1}+\vartheta_{1} \cdot i_{X L}-\vartheta_{2} \cdot i_{X R}+g_{F X}\left(\vartheta_{1}-\vartheta_{2}\right)-g_{Y}
\end{aligned}
$$

Onde $\overline{\bar{s}^{\prime}}{ }_{x}^{t+1}=S_{x}^{t+1} / D X L ; \vartheta_{1}=F X . X L / D X L ; \vartheta_{2}=F X . X R / D X L$.

A evolução da dívida externa líquida como proporção do PIB depende positivamente do déficit comercial $\left(S^{\prime}{ }_{x}\right)$, da taxa de juros incidente sobre o estoque de dívida externa e da oscilação da taxa de câmbio. Adicionalmente, há dependência de modo negativo da taxa de crescimento da economia e da taxa de remuneração das reservas internacionais.

Nos termos da taxonomia de Minsky (1986), uma estrutura externa tipicamente hedge pode ser associada a um superávit de conta-corrente $\left(S_{x}^{t+1} \leq 0\right)$. Esta posição, do ponto de vista doméstico, gera uma tendência de apreciação da taxa de câmbio, dada pelo aumento da disponibilidade de divisas no país; que pode ser mitigada ou anulada por processos de esterilização cambial por parte do banco central, que resultam em elevação das reservas internacionais.

Uma posição deficitária em conta-corrente possui como correspondência nos balanços domésticos, uma necessidade líquida de financiamentos externo positiva $\left(S_{g}+\right.$ $\left.S_{p}-I<0\right)$, resultando numa condição financeira alavancada. Esta conformação é especulativa se as taxas esperadas de crescimento da renda superam ou equivalem à somatória dos ônus gerados pelo saldo comercial negativo e pelos encargos de juros proveniente do estoque da dívida externa líquida anterior, como expresso em (19). Neste caso, pode haver um aumento absoluto do endividamento externo com redução ou manutenção de seu nível relativo. A sustentabilidade da posição externa depende não somente da capacidade de geração de divisas da economia e da taxa de crescimento econômico, mas também das condições financeiras externas. À medida que a dívida externa esperada apresente uma tendência crescente em relação ao PIB, evidencia-se uma situação Ponzi $i^{8}$.

$$
{\overline{\overline{s^{\prime}}}}_{x}^{t+1}+\vartheta_{1} \cdot i_{X L}-\vartheta_{2} \cdot i_{X R}+g_{F X}\left(\vartheta_{1}-\vartheta_{2}\right) \leq g_{Y}
$$

$\mathrm{O}$ endividamento em moeda estrangeira contribui para que os setores domésticos se tornem vulneráveis a descasamentos de moedas, comprometendo a capacidade financeira dos setores domésticos. A prociclicidade com que a disponibilidade de recursos se apresenta contribui para que a dinâmica de fragilidade financeira seja amplificada (Eichengreen et ali, 2002; Akyüs, 2008; Ocampo, 2011; Taylor, 2001).

Outro ponto relevante se relaciona aos estímulos à alavancagem provenientes do exterior, eminentemente exógenos. Os fluxos de capital externo não respondem

(8) Partindo da análise de sustentabilidade externa de uma economia com déficit em conta-corrente, Barbosa-Filho (2001) avalia que, dados os parâmetros estruturais de comércio exterior, a sustentabilidade externa de uma economia pequena depende da oscilação de parâmetros associados ao dinamismo da economia externa e ao endividamento externo (taxas de juros reais internacionais e risco país). A gestão da política macroeconômica fica condicionada à condição de equilíbrio de balanço de pagamentos. Períodos de alta dos encargos da dívida externa ou redução do dinamismo externo demandam esforço de ajuste doméstico por parte das autoridades macroeconômicas, com vistas ao alcance de níveis de exportações e importações a níveis compatíveis com uma trajetória não crescente da dívida externa. 
passivamente à demanda por parte dos setores domésticos deficitários, como discutido na seção anterior. Decorrem de decisões tomadas pelas instituições financeiras internacionais, que em grande parte são influenciadas pelo ambiente de percepção de riscos prevalecente em suas matrizes. Do mesmo modo que podem ser excessivos em condições de elevada liquidez global e apetite a riscos, podem proporcionar paradas súbitas de ingressos e rolagens de dívida para os países devedores, por condições alheias a seus ciclos ou capacidade de pagamento.

Como discutido por Taylor (2001), as crises financeiras não se resumem à antecipação racional de um setor privado alerta às falhas dos policy makers. Pelo contrário, se relacionam a um contexto em que os agentes privados, domésticos e estrangeiros, buscam incessantemente oportunidades de lucros, e no qual o comportamento do setor público possui fatores de incentivo que atuam de modo procíclico, respaldados pelas expectativas vigentes. Há um componente dinâmico, que se associa à mudança da condição financeira dos mesmos devedores e da disposição dos credores ao risco ao longo do tempo.

\section{Considerações finais}

Este trabalho buscou trazer elementos para a discussão sobre a instabilidade financeira em PEDs, avaliando condicionantes e impulsos presentes na atividade dos principais setores presentes numa economia, com foco no caso de países em desenvolvimento. Como discutido por Taylor (2001), crises financeiras não correspondem à reação de agentes privados alertas às distorções causadas ao risco de crédito dos devedores. Podem ser compreendidas como resultado de um processo em que agentes privados, credores e devedores, com a finalidade de maximização de lucros, adotam posturas alavancadas ao longo dos períodos de crescimento, corroborando para o surgimento de fragilidades.

Do ponto de vista dos setores domésticos, a busca privada por lucros extraordinários, própria do processo concorrencial capitalista, incentiva a tomada de decisões arriscadas e pune comportamentos conservadores em relação ao risco nos períodos de crescimento. $\mathrm{O}$ oposto se verifica nos períodos de acirramento de incerteza. No caso do Estado, embora seu objetivo de atuação se diferencie, por meio de um papel estabilizador e anticíclico, como enfatizado por Minsky (1986), podem ser notados mecanismos de incentivo procíclicos que reduzem sua capacidade de ação.

Um ponto importante a ser observado em relação aos PEDs é a natureza dos problemas econômicos, que difere da realidade típica de economias avançadas. A existência de relações assimétricas do ponto de vista produtivo, como ressaltado pela literatura estruturalista e por modelos pós-keynesianos de crescimento, contribui para a ocorrência frequente de episódios de instabilidade decorrentes da escassez de divisas. Adicionalmente, a natureza procíclica dos fluxos de capital, num contexto de assimetrias nos sistemas monetário e financeiro internacionais, contribui para o aumento da amplitude dos períodos de dos períodos de boom e bust. Com isto, há nos PEDs uma perda de força dos instrumentos tradicionais de ação do Estado nos períodos de instabilidade, comentados por Minsky (1986), relacionados ao big bank e big government. Cabe aos governos um tipo de atuação com foco além do âmbito doméstico e interligado com elementos estruturais da economia. 
A indexação de compromissos externos em moeda estrangeira diminui sua capacidade de aumentar seus gastos como forma de estimular a economia e sanear os setores em dificuldade. Torna-se fundamental a construção de mecanismos que contribuam para que o Estado aja de modo efetivamente anticíclico, o que significa sua habilidade de navegar contra a maré nos períodos de bonança e de constituição de mecanismos de prevenção macroprudenciais, que visem sobretudo maior capacidade de gerenciamento sobre fluxos de entrada e saída de capital, de oscilações da taxa de câmbio e da exposição em moeda estrangeira dos agentes domésticos.

Uma série de mecanismos de controle de captais têm sido adotados por países desde o pós-crise de 2008, com vistas a evitar efeitos colaterais de entradas abruptas de capitais. O reconhecimento da viabilidade destes expedientes por parte do FMI revela que a liberalização excessiva das contas financeiras, especialmente em praças consideras especulativas, tende a ser danosa para a estabilidade financeira, como discutido por Prates e de Paula (2017).

Como discutido por Ocampo (2011), o acúmulo de reservas internacionais por PEDs tem permitido o controle simultâneo das taxas de juros e do câmbio, mesmo em cenários de mobilidade de capitais. Sua manutenção tem ampliado margens de manobra para a adoção de políticas monetárias expansivas nos períodos de maior instabilidade, contribuindo para atenuar os efeitos dos influxos de capital nos ciclos expansivos, e servindo como instrumento de proteção nas retrações.

A observação de que períodos de instabilidade podem ser advindos de relações financeiras internacionais e de que crises financeiras possuem maior capacidade de atravessar fronteiras suscita a discussão sobre limitações de ações dos Estados de modo isolado e sobre a necessidade de instrumentos ou entidades que atuem em nível internacional. A experiência das últimas décadas tem evidenciado que os mecanismos multilaterais atualmente existentes possuem alcance limitado e insuficiente, justificando o debate sobre reformas (Carvalho; Kregel, 2009; Taylor, 2001).

Os períodos de bonança podem conferir janelas de oportunidades para a adoção de medidas corretivas de vulnerabilidades, com vistas a reduzir a condição de "reféns dos mercados" típicas dos períodos de retração. Porém, de modo análogo ao discutido por Minsky (1986), a evolução das expectativas calcada no sucesso recente, e a sensação de segurança típica dos períodos de crescimento, reduzem os incentivos para mudanças e aumentam a sensação de que it can't happen again, o que constitui um desafio adicional para uma visão evolutiva, mesmo quando as raízes da vulnerabilidade ainda estejam presentes.

\section{Bibliografia}

AGLIETTA, M. Lidando com o risco sistêmico. Economia e Sociedade, Campinas, n. 11, p. 1-32, dez. 1998.

AKYÜS, Y. Managing financial instability in emerging markets: a keynesian perspective. Turkish Economic Association, 2008. (Discussion Paper, n. 4). 
AMADO, A.; RESENDE, M. F. Liquidez internacional e ciclo reflexo: algumas observações para a América Latina. Revista de Economia Política, v. 27, n. 1, jan. 2007.

ARBACHE, J: Competitividade internacional e políticas públicas. 2013. Disponível em: http://www.arbache.com/blog/2013/08/competitividade-internacional-e-

pol\%C3\%ADticas-p\%C3\%BAblicas.html

BALDWIN, R.; ITO, T.; SATO, H. The smile curve: evolving sources of value added in manufacturing. In: INTERNATIONAL CONFERENCE ON "ECONOMICS OF GLOBAL INTERACTIONS: NEW PERSPECTIVES ON TRADE, FACTOR MOBILITY AND DEVELOPMENT, 5, Bari, set. 2014.

BARBOSA-FILHO, N. The balance-of-payments constraint: from balanced trade to sustainable debt. PSL Quarterly Review, Roma, v. 54, n. 219, 2001.

BARBOSA-FILHO, N. Resultado primário, dívida líquida e dívida bruta: um modelo contábil. In: WP Brasil Debate, ago. 2014. Disponível em: http://brasildebate.com.br/wpcontent/uploads/2014/08/Modelo-Contabil.pdf.

BIELCHOVSCHY, R. Cinquenta anos de pensamento na Cepal - uma resenha. In: BIELCHOVSCHY, R: Cinquenta anos de pensamento na Cepal. Rio de Janeiro: Editora Record, 2000. v. 1. p. 13-68.

BLAUG, M. Economic theory in retrospect. $5^{\text {th }}$. ed. Cambridge: Cambridge University Press, 1997.

BRAGA, J. C. S.; CINTRA, M. A. M. Finanças dolarizadas e capital financeiro: exasperação sob comando americano. In: FIORI, J. L. (Org.). O poder americano. Petrópolis: Editora Vozes, 2004.

CARVALHO, F. C. J. Fundamentos da escola pós-keynesiana: a teoria de uma economia monetária. Rio de Janeiro: UFRJ/IEI, 1988. (Texto para Discussão, n.176).

CARVALHO, F. C.; KREGEL, J. Crise financeira e déficit democrático. Rio de Janeiro: Ibase, 2009.

CINTRA, M. A. M.; FARHI, M. A crise financeira e o shadow banking system. Novos Estudos - CEBRAP, São Paulo, n. 82, p. 35-55, nov. 2008.

CHICK, V. Macroeconomics after Keynes: a reconsideration of the general theory. MIT Press, 1983.

CHICK, V. A evolução do sistema bancário e a teoria da poupança, do investimento e dos juros. Estudos FEE, Porto Alegre, v. 15, n. 1, p. 9-23, 1994.

DAVIDSON, P. Uncertainty in economics. In: DOW, S.; HILLARD, J. (Ed.). Keynes, knowledge and uncertainty. Hants: Edward Elgar, 1995. p. 107-116.

DAVIDSON, P. The post Keynesian school. In: SNOWDOWN, B.; VANE, H. In: MODERN macroeconomics. Chelteham, UK/Northampton, USA: Edward Elgar, 2005.

EICHENGREEN, B.; HAUSMANN, R.; PANNIZZA, U. Original Sin: the pain, the mystery, and the road to redemption. Documento apresentado para a conferência "Currency 
and Maturity Matchmaking: Redeeming Debt from Original Sin. Washington, D.C.: InterAmerican Development Bank, 21-22 Nov. 2002. Disponível em: http://www.financialpolicy.org/financedev/hausmann2002.pdf.

FAINZYLBER, F. Industrialização na América Latina: da "caixa-preta" ao "conjunto vazio". In: BIELCHOVSCHY, R. Cinquenta anos de pensamento na Cepal. Rio de Janeiro: Editora Record, 2000. v. 2, p. 851-886.

FFRENCH-DAVIS, R. Esbozo de un planteamiento neoestructuralista. Revista de la Cepal, Santiago, n. 34, abr. 1988.

FISHER, I. The debt-deflation theory of great depressions. Econometrica, v. 1, n. 4, p. 337-357, Oct. 1933.

FOLEY, D. Financial fragility in developing economies. New School University, 2001. Mimeo.

FREITAS, M. C. P. A natureza particular da concorrência bancária e seus efeitos sobre a estabilidade financeira. Economia e Sociedade, n. 8, jun. 1997.

FREITAS, J. T. Acordo de Basileia 2 e estabilidade financeira em países em desenvolvimento. 2008. Dissertação (Mestrado)-Instituto de Economia, Universidade Estadual de Campinas, Campinas, 2008.

FREIXAS, X.; ROCHET, J. C. The microeconomics of banking. Cambridge: MIT Press, 2008.

FURTADO, C. Desenvolvimento e subdesenvolvimento. In: BIELCHOVSCHY, R. Cinquenta anos de pensamento na Cepal. Rio de Janeiro: Editora Record, 2000. v. 1, p. 239-262.

GODLEY, W.; LAVOIE, M. Monetary economics: an integrated approach to credit, money, income, production and wealth. Palgrave Macmillan, 2007.

GRIFFITH-JONES, S.; KREGEL, J.; OCAMPO, J. A. International finance and development. New York: Orient Longman Publications, 2007.

GRIFFITH-JONES, S.; OCAMPO, J. A. A countercyclical framework for a developmentfriendly international financial architecture. Desa Working Papers, n. 39, 2007.

GROS, D.; ALCIDI, C.; GIOVANNI, A. Central Banks in times of crisis: the FED vs. the ECB. CEPS Policy Brief, n. 276, Jul. 2012.

IMF. The liberalization and management of capital flows: an institutional view. IMF Policy Papers, Washington D.C., Nov. 2012.

KAMINSKY, G.; REINHART, C.; VÉGH, C. When it rains, it pours: procyclical capital flows and macroeconomic policies. NBER Macroeconomics Annual 2004, MIT Press, v. 19, Apr. 2005. Disponível em: http://www.nber.org/chapters/c6668.pdf.

KEYNES, J. M. (1936) A Teoria Geral do Emprego, do Juro e da Moeda. São Paulo: Atlas, 1996. (Coleção "Os Economistas"). 
KEYNES, J. M. The General Theory of employment. Quartely Journal of Economics, v. 51, p. 209-223, 1937a.

KEYNES, J. M. The ex ante theory of the rate of interest. Economic Journal, v. 47, n. 188. p. 663-669, Dic. 1937 b.

KEYNES, J. M. (1937c). Alternative theories of the rate of interest. In: THE COLLECTED Writings of John Maynard Keynes. Macmillan / Cambridge University Press, 1973. v. XIV, p. 201-215.

KINDLEBERGER, C. Manias, pânico e crashes: um histórico das crises financeiras. Saraiva, 2000.

KING, J. Post Keynesian economics. In: DURLAUF, S.; BLUME. L. The New Palgrave dictionary of economics. $2^{\text {nd }}$ ed. 2008 Disponível em: http://www.dictionaryofeconomics.com/dictionary.

KREGEL, J. Can we create a stable international financial environment that ensures net resource transfers to developing countries? Journal of Post Keynesian Economics, v. 26, n. 4, p. 573-590, Summer 2004.

LE HERON, E.; MOUAKIL, T. A post-Keynesian stock-flow consistent model for dynamic analysis of monetary policy shock on banking behavior. Metroeconomica, v. 59, n. 3, p. 405-440, 2008.

MINSKY, H. John Maynard Keynes. New York: Columbia University Press, 1975.

MINSKY, H. Stabilizing an unstable economy. New Haven: Yale University Press, 1986.

MINSKY, H. Capital flows, interest payments and the balance of-payments constrained growth model: a theoretical and empirical analysis. Metroeconomica, v. 54, n. 2-3, p. 346365, 2003.

MORENO-BRID, J. C. Capital flows, interest payments and the balance-of-payments constrained growth model: a theoretical and empirical analysis. Metroeconomica, v. 54, n. 2-3, p. 346-365, 2003.

NIELSEN, L. Classifications of countries based on their level of development: how it is done and how it could be done. IMF Working Papers, n. 11/31, Feb. 2011.

NIKIFOROS, M.; ZEZZA, C. A simplified stock-flow consistent post-Keynesian growth model. The Levy Economics Institute of Bard College, May 2017. (Working Paper, n. 891).

OCAMPO, J. Macroeconomía para el desarrollo: políticas anticíclicas y transformación productiva. Revista de la CEPAL, n. 104, p. 29-32, ago. 2011.

PALLEY, T. The theory of global imbalances: mainstream economics vs. structural Keynesianism. Global crisis and the need for paradigm change. In: Colóquio Internacional de Economia, 9, Brasília, Maio 2014.

PAPADIMITROU, D.; WRAY, R. Introduction to Minsky's stabilizing an unstable economy. In: MINSKY, H. Stabilizing an unstable economy. McGraw-Hill, 2008. 
PRATES, D. Crises financeiras nos países emergentes: uma interpretação heterodoxa. 2004. Tese (Doutorado)-Instituto de Economia, Universidade Estadual de Campinas, Campinas, 2004.

PRATES, D.; DE PAULA, L. F. Capital account regulation in Brazil: an assessment of the 2009-2013 period. Brazilian Journal of Political Economy, v. 37, n. 1 (146), p. 108-129, Jan./Mar. 2017.

PREBISCH, R. (1949). O desenvolvimento econômico da América Latina e alguns de seus principais problemas. In: BIELCHOVSCHY, R. Cinquenta anos de pensamento na Cepal. Rio de Janeiro: Editora Record, 2000. v. 1, p. 69-136.

RODRIGUEZ, O. O estruturalismo latino-americano. Rio de Janeiro: Civilização Brasileira, 2009.

SANTOS, C., ZEZZA, C. Stock-flow consistent macroeconomic models: a survey. The Levy Economics Institute of Bard College, Apr. 2005. (Working Paper, n. 421).

SANTIAGO, S. A inserção da América Latina no sistema centro-periferia, no contexto de finanças globalizadas: observações para México, Brasil e Argentina. Tese (Doutorado)Universidade de Brasília, 2016.

SARDONI, C. How to deal with the public debt: ideas from Keynes, Lerner, Domar and Hicks. Sapienza University of Rome, 2013. Mimeo. Disponível em: http://iippe.org/wp/wp-content/uploads/2013/06/Claudio-Sardoni.pdf.

SNOWDOWN, B.; VANE, H. Modern macroeconomics. Chelteham, UK / Northampton - USA: Edward Elgar Davidson, 2005.

SUNKEL, O.; ZULETA, G. neoliberalismo versus neoestructuralismo: la politica de desarrollo en la encrucijada de los noventa. In: LOS TEMAS CEPAL-PREBISCH, Semináio, Santiago, Cepal. Set. 1990.

TAVARES, M. C. A retomada da hegemonia americana. Revista de Economia Política, v. 5, n. 2. p. 5-15, abr./jun. 1985.

TAVARES, M. C. O processo de substituição de importações como modelo de desenvolvimento na América Latina/ O caso Brasil. In PETRELLI, V.; SIMIONI, M. Desenvolvimento e igualdade. Homenagem aos 80 anos de Maria de Conceição Tavares. Brasília: IPEA, 2011.

TAVARES, M. C.; MELIN, L. E. (1997): Pós-escrito de 1997: A reafirmação da hegemonia americana. In TAVARES, M.C. e FIORI, J. L. (1997). Poder e dinheiro: Uma economia política da globalização. Petrópolis. Vozes.

TAYLOR, L. (2001): Capital market crises: liberalization, fixed exchange rates and market-driven destabilization. Chang, H., Palma, G. Whittaker, D. :Financial Liberalization and the Asian Crisis. Palgrave.

THIRWALL, A. The balance of payments constraint as an explanation of international growth rate differences. Banca Nazionale del Lavoro Quarterly Review, Roma, v. 32, Mar, 1979. 
THIRWALL, A. Balance of payments constrained growth models: history and overview. PSL Quarterly Review, v. 64, n. 259, p. 307-351, 2011.

WOLFSON, M. (2000). Minsky's theory of financial crisis in a global context. Journal of Economic Issues, v. XXXVI, n. 2, Jun. 2002.

WRAY, R. Money and inflation. CFEPS, Sept. 2000. (Working Papers, n. 12). Disponível em: http://www.cfeps.org/pubs/wp-pdf/WP12-Wray.pdft. 